\title{
Economic Actors in EU Environmental Law
}

Carolyn Abbot and Maria Lee*

\section{Introduction}

The inclusion of private actors in EU environmental governance, and indeed in other areas of regulation at all levels, is absolutely routine. A 'decentred' approach to regulation and governance recognises that private parties hold key resources that may enhance any aspect of the regulatory process, from information provision, to standard-setting, to enforcement. ${ }^{1}$ In many instances, the state formally harnesses these resources, thereby facilitating the constructive activities of private parties in this regard. An enormous range of private (nonstate, non-EU) actors participate in regulation, including industry and environmental organisations. We are concerned here with the role of 'economic actors', ${ }^{2}$ including the regulated industry, or even the individual regulated company, ${ }^{3}$ in EU environmental governance.

In this paper, we acknowledge that the inclusion of economic actors in environmental governance is crucial for environmental protection; but equally that their role does raise some significant concerns, particularly in terms of accountability and (input and output) legitimacy. We examine below the efforts made in EU environmental law to respond to those concerns, and argue that EU law has developed important safeguard mechanisms to address concerns about economic actors. Those mechanisms are, however, applied in a flawed and inconsistent manner. We therefore explore some additional methods for mitigating the challenges posed by actors in regulation, which build on the approaches already entrenched in EU law. It is not suggested that, even if perfectly implemented, there is any way easily to escape the difficulties posed by the role of economic actors in regulation. So we are not proposing any overarching single solution to the challenges posed. Borrowing

\footnotetext{
* University of Manchester and UCL. We are very grateful to Joanne Scott, Elen Stokes and David Williamson for reading earlier drafts of this paper, and to participants at the Society of Legal Scholars annual conference in September 2013 and at the Francis Taylor Building Academic Panel Round Table in December 2013 for their helpful comments. Frances Bodman provided excellent research assistance.

${ }^{1} \mathrm{~J}$. Black, 'Decentring Regulation: Understanding the Role of Regulation and Self-Regulation in a 'Post-Regulatory' World' (2001) 54 Current Legal Problems 103. This is true of many area of 'governance' and 'regulation' scholarship, in the EU most notably the families of governance known as 'new' or 'experimentalist' governance, see eg the discussion in M. Lee, EU Environmental Law, Governance and Decision-Making (Oxford: Hart Publishing, 2014), Chapter 4.

2 Using the language of B. Hutter, The Role of Non-State Actors in Regulation (2006, CARR Discussion Paper No. 37).

${ }^{3}$ The notion of 'economic actor' may include also eg suppliers, trade organisations, professional advisors, etc, see Hutter, ibid.
} 
from de Búrca's discussion of democracy-striving approaches to transnational (global) governance, we think that when perfect solutions are not available, it is important to 'strive' for even imperfect legitimacy and accountability. ${ }^{4}$

Economic actors play a significant role in many areas of EU environmental law, from the regulation of genetically modified organisms (eg preparing risk assessment under the Deliberate Release Directive), ${ }^{5}$ to the environmental assessment of projects (eg preparing environmental statements under the Environmental Impact Assessment Directive) ${ }^{6}$ In this paper, we explore the role of economic actors in the implementation of two pieces of EU environmental legislation: the Industrial Emissions Directive 2010 (IED), ${ }^{7}$ and the REACH (Registration, Evaluation, Authorisation and Restriction of Chemical Substances) Regulation $2006 .^{8}$ As discussed below, these two major pieces of EU environmental law, addressing different parts of the governance landscape, rely heavily on economic actors for their elaboration and implementation and illustrate the ubiquity of economic actors in command and control regulation. ${ }^{9}$ Whilst both are relatively recent pieces of legislation (although the IED is successor to the Integrated Pollution Prevention and Control (IPPC) Directive 1996), ${ }^{10}$ the involvement of economic actors in governance is certainly not a new development. Most obviously, for example, the dominant role of economic actors in product standardisation is well known, and has been strongly linked to legal compliance under the EU's 'new approach' to standardisation since the mid-1980s. ${ }^{11}$ However, Grabosky's observation of an 'increase in the number and activity of nongovernmental participants in the regulatory process' which he associates with the weakening of state regulatory activities, is certainly plausible. ${ }^{12}$

4 G. de Búrca, 'Developing Democracy Beyond the State' (2008) 46 Columbia Journal of Transnational Law 221. De Búrca's discussion takes place in a very different context, and one important distinction relates to the ability in the EU, notwithstanding the debate about the EU's democratic deficit, to link decisions with purportedly democratic processes in the EU.

5 Directive 2001/18/EC on the deliberate release into the environment of genetically modified organisms [2001] OJ L106/1.

${ }^{6}$ Directive 2011/92/EU on the assessment of the effects of certain public and private projects on the environment (codification) [2012] OJ L26/2 as amended by Directive 2014/52/EU [2014] OJ L121/1.

${ }^{7}$ Directive 2010/75/EU on industrial emissions (integrated pollution prevention and control) [2010] OJ L334/17.

${ }^{8}$ Regulation 1907/2006/EC concerning the Registration, Evaluation, Authorisation and Restriction of Chemicals (REACH), establishing a European Chemicals Agency [2006] OJ L396/1.

${ }^{9}$ See generally E. Stokes, 'Demand for Command: Responding to Technical Risks and Scientific Uncertainties' (2013) 21 Medical Law Review 11.

10 Directive 1996/61/EC on integrated pollution prevention and control [1996] OJ L 257/26.

${ }^{11}$ See for example H. Schepel, The Constitution of Private Governance: Product Standardisation in the Regulation of Integrating Markets (Oxford: Hart Publishing, 2005).

12 P. Grabosky, 'Beyond Responsive Regulation: The Expanding Role of Non-State Actors in the Regulatory Process (2013) 7 Regulation and Governance 114,at 114. 
We do not suggest that our two selected pieces of legislation are either unique or uniquely revealing, but they do allow us to make observations that apply more broadly when economic actors are involved in EU environmental (and other) law. After outlining some of the ways in which economic actors are involved in these two areas of environmental governance, we explore the many good reasons for that involvement, especially economic actors' possession of, or ability to obtain, crucial resources of information or knowledge. Populating the regulatory space with economic actors can potentially enhance the legitimacy and accountability of decision-making. However, paradoxically, their involvement can also create significant tensions, especially in terms of legitimacy and accountability. Despite these concerns, rejecting their involvement would not only be unrealistic, but probably also counterproductive for environmental protection. Much can be learned, for example, from the history of chemicals regulation, which as discussed below was painfully slow when it relied on information generated by public sector regulators. More generally, and more profoundly, different strands of regulatory scholarship are consistent in emphasising the social fragmentation of knowledge and authority, and the implausibility of a single government agency exercising control over complex social problems. ${ }^{13}$ Accepting that economic actors play an important role in the implementation of the IED and $\mathrm{REACH}$, we consider the (limited) safeguards that have been provided in an effort to ensure the continued legitimacy and accountability of the governance framework.

We identify three key legal safeguards: inclusion; transparency; and public oversight and responsibility. The inclusion of a range of private and public actors, extending beyond the industry involved, should be designed (at least) to avoid the dominance of any single set of interests or perspectives. Transparency in decision-making is a routine part of any recipe to improve legitimacy, and although both its meaning and its implementation can be complicated, transparency is a necessary starting point for any political or legal challenge to processes and decisions. And finally, public oversight and responsibility has two elements. On the one hand, public regarding (or regulatory) institutions are one dimension of inclusion and transparency, in the sense that the public institutions are one of the private actors' accountees. On the other hand, making public institutions ultimately responsible for a final decision attempts to side-step concerns about economic actor involvement in that decision. At its best, it can ensure that a politically legitimate decision-maker takes important political decisions on environmental quality and its costs; at its worst, it may be an attempt to avoid engaging with the reality and complexity of governance, providing simply a highly formalistic

\footnotetext{
${ }^{13}$ See, for example, L. Hancher and M. Moran, 'Organizing Regulatory Space' in L. Hancher and M. Moran (eds.) Capitalism, Culture and Economic Regulation (Oxford: Clarendon Press, 1989); Black, above $\mathrm{n}$ 1; Schepel, above $\mathrm{n} 11$.
} 
reflection of the theoretical limits of delegated power. We explore each of these safeguards, and their limitations, below. They all have a place in the IED and REACH, implying at least some legal awareness of their importance, as well as their potential feasibility and workability more generally. Less optimistically, however, IED and REACH institutionalise these safeguards in an ad hoc and flawed way, and we suggest that there are further and more demanding responsibilities for law in this respect.

\section{The Place of Economic Actors in the IED and REACH}

The IED and REACH deal with different parts of the environmental regulatory landscape: the IED regulates a process, specifically major industrial operations; $\mathrm{REACH}$ regulates products, specifically chemicals, which enjoy free movement in the EU internal market. The role played by economic actors in each case is also slightly different. In $\mathrm{REACH}$, economic actors provide the basic information on which the regulation (or informal governance by third parties, eg citizen or consumer pressure) of their products will be based. This includes the preparation of a risk assessment and a cost benefit (or socio-economic) assessment for the purposes of authorisation of chemicals identified as being 'of very high concern'. REACH is in this respect essentially a more ambitious version of the common-place pattern of regulation, in which the party seeking authorisation of an activity, product or development provides the information underlying the regulatory process. Under the IED, economic actors play a somewhat different role, collaborating with each other and with a range of other private and public actors to generate some of the central norms underpinning the application of the Directive to individual facilities. Again, this is not an isolated example: it bears some similarities with product standardisation, and also with the Common Implementation Strategy under the Water Framework Directive 2000. ${ }^{14}$

The institutional arrangements set up by the two pieces of legislation differ accordingly. The IED has put in place an elaborate institutional framework for the engagement of particular privileged participants. REACH is an apparently (although in practice not entirely, note for example the obligations to pass information up and down the supply chain and joint submissions) ${ }^{15}$ more individualised activity, in which particular actors in the industry, especially but not exclusively producers and importers of chemicals, are obliged to provide information on their substances.

\footnotetext{
14 Directive 2000/60/EC establishing a framework for Community action in the field of water policy [2000] OJ L 327/1. See further, M. Lee, 'Law and Governance of Water Protection Policy' in J. Scott (ed.), Environmental Protection: European Law and Governance (Oxford University Press, 2009).

${ }^{15} \mathrm{~J}$. Scott, 'REACH: Combining Harmonization and Dynamism in the Regulation of Chemicals' in Scott, ibid.
} 
The IED is the main piece of legislation applying to industrial pollution in the EU, including major industrial activities, such as chemical and energy industries, as well as certain intensive farming operations. The IED is, on the face of it, a classic example of direct or command-and-control regulation. Installations listed in Annex I must apply for a permit, attached to which are standards designed to minimise the environmental impacts of the regulated activity. The role of economic actors in the application for permits under the IED should be noted: the operator seeking authorisation provides the first draft of the information on which permitting decisions are based. ${ }^{16}$ The focus of this paper is, however, on the drafting of BAT Reference Documents (BREFs). 'Best available techniques' (BAT) plays a very important role in the IED. Article 11 IED sets out certain 'general principles governing the basic obligations of the operator', which must be applied and enforced by national and local regulators; this includes the requirement that 'the best available techniques are applied'. Article 14 sets out minimum conditions for the permits, which must ensure compliance with the general principles, including therefore with BAT. Emission limit values (ELVs) must be set for certain pollutants; some quantitative ELVs are specified in the Annexes to the Directive; others are set in accordance with what would be achieved by BAT.

BAT is defined in Article 3(10) of the Directive at some length, but in very open terms: BAT is

'the most effective and advanced stage in the development of activities and their methods of operation which indicates the practical suitability of particular techniques for providing the basis for emission limit values and other permit conditions designed to prevent and, where that is not practicable, to reduce emissions and the impact on the environment as a whole.'

The different elements of BAT are further defined:

'(a) 'techniques' includes both the technology used and the way in which the installation is designed, built, maintained, operated and decommissioned; (b) 'available techniques' means those developed on a scale which allows implementation in the relevant industrial sector, under economically and technically viable conditions, taking into consideration the costs and advantages, whether or not the techniques are used or produced inside the Member State in question, as long as

${ }^{16}$ Art 12. 
they are reasonably accessible to the operator; (c) 'best' means most effective in achieving a high general level of protection of the environment as a whole.'

Annex III provides twelve additional 'criteria for determining best available techniques', including eg 'the use of low waste technology', 'the consumption and nature of raw materials (including water) used in the process and energy efficiency' and 'information published by public international organisations'.

So the Directive provides detailed direction to regulators on the meaning of BAT. But BAT nonetheless remains an open-ended, flexible, even vague term. The IED indicates the sorts of things that might be relevant in any case, but not how they will be assessed or used in decision-making, and no single 'correct' outcome seems to be envisaged: even following the Directive's demands very carefully could lead to a range of possible conclusions on BAT. As is fairly common in EU environmental law, this open-ended term is further spelled out and defined beyond the legislation, in this case through what is known as the 'Seville process', so-called for the central role of the European IPPC Bureau, based in Seville . ${ }^{17}$ The Seville process brings together different actors for the drafting of BAT Reference Documents (BREFs), which are lengthy documents that set out BAT in more detail for particular issues or sectors. BREFs contain 'BAT Conclusions', which constitute 'the reference' for setting permit conditions, and when adopted by the Commission (with comitology - discussed below), provide emission limit values that are prima facie mandatory. ${ }^{18}$

The Commission decides when to draw up and review a BREF. ${ }^{19}$ The initial 'exchange of information' on BAT takes place in a Technical Working Group (TWG), composed of 'Member States, the industries concerned, non-governmental organisations promoting environmental protection and the Commission'. ${ }^{20}$ The legal requirements for inclusion in the TWGs are relatively even-handed between industrial and environmental interests, although other interests, such as trade unions, are notable by their absence. As discussed further below, however, economic actors are (at least quantitatively) heavily represented in the TWGs; information made available by the European IPPC Bureau (on request) indicates that seven organisations classified as an 'environmental NGO' take part in TWGs, compared to

17 For fascinating detail see B. Lange, Implementing EU Pollution Control: Law and Integration. (Cambridge University Press, 2008).

${ }^{18}$ Art 14(3); Art 15(3). See further Lee, above $n 1$.

${ }^{19}$ Art 13.

${ }^{20}$ Art 13(1). 
over 250 classed as an 'industrial NGO'. ${ }^{21}$ Of 44 participant organisations in the TWG that drafted the BREF for iron and steel production, it appears that two were environmental interest groups (the EEB and ÖKOPOL ${ }^{22}$ ), 14 were from industry, and the rest represented the Member States: Denmark, Finland, Germany, Greece, Hungary, Ireland, Luxemburg, Poland, Slovenia, Spain, Sweden and the UK were each represented by one organisation; Belgium and France, two; Portugal three; Italy four; and the Netherlands five.

The Commission must also 'establish and regularly convene' a forum, composed of 'Member States, the industries concerned, non-governmental organisations promoting environmental protection'. ${ }^{23}$ Members of the Forum are responsible for nominating members ('their representatives') to the TWGs. ${ }^{24}$ No names are provided on the Commission's Register of Expert Groups, ${ }^{25}$ but information on affiliations and groups confirms that industry is heavily represented: three members of the forum are classified as 'NGO' (and seem to be environmental interest groups), and 55 as 'international organization' (and seem to be industry groups). The Forum provides an 'opinion' on the content of the BREF proposed by the TWG.$^{26}$ The opinion is made public, and must be taken into account by the Commission when it presents draft BAT Conclusions to the comitology committee.

Turning to REACH, this piece of legislation applies to all chemicals imported or manufactured in the EU. Manufacturers or importers of more than one tonne of any 'substance' 27 per year must register that substance, ${ }^{28}$ which essentially requires economic actors to provide the European Chemicals Agency (ECHA) with a range of information, more information (as set out in Annexes $\mathrm{VI}$ to $\mathrm{X}$ ) as ten, 100 and 1000 tonne thresholds are passed. ${ }^{29}$ The registration, and information provision, obligations imposed on economic actors by REACH are central to the operation of the rest of the Regulation. The 'privatisation' of information provision, collection and assessment has been identified as one of the key

\footnotetext{
${ }^{21}$ European IPPC Bureau, Email communication with Maria Lee, 25 July 2012. Further information has been made available during more prolonged correspondence, and is on file with the authors.

22 OKOPOL is appropriately described as an NGO, but should not be thought of (as per its own selfdescription) as an environmental advocacy organisation; it is much more concerned with its scientific credentials, and clearly works closely with public authorities and industry, www.oekopol.de/en/.

${ }^{23}$ Art 13(3).

${ }^{24}$ Commission Implementing Decision 2012/119/EU laying down rules concerning guidance on the collection of data and on the drawing up of BAT reference documents and on their quality assurance [2012] OJ L63/1.

${ }_{25}$ See ec.europa.eu/transparency/regexpert/index.cfm, last accessed June 2014.

26 Art 13(4).

27 'Substance: means a chemical element and its compounds in the natural state or obtained by any manufacturing process, ...', Art 3(1).

${ }^{28}$ Art 6.

${ }^{29}$ Art 12.
} 
characteristics of $\mathrm{REACH},{ }^{30}$ although that privatisation is not untrammelled. The role of information in $\mathrm{REACH}$ is in part simply to provide regulators with the information necessary for decisions, for example as to categorisation as a 'substance of very high concern' (SVHC) or on authorisation. The expectation is also that there will be effects in the market, as consumers (including sophisticated commercial operators, or consumers responding to campaigns organised by NGOs) demand action.

The obligation to seek authorisation for the use of an SVHC is the 'command and control' element of REACH. SVHCs are the most hazardous chemicals, covering those classed as carcinogenic, mutagenic or toxic for reproduction (CMR), persistent, bioaccumulating and toxic (PBT) and very persistent and very bioaccumulating (vPvB), as well as substances 'for which there is scientific evidence of probable serious effects to human health or the environment which give rise to an equivalent level of concern'. ${ }^{31}$ The information provided by industry on registration is likely in most cases to be central to the decision to classify a substance as a SVHC, although a substance can be an SVHC regardless of the quantity imported or manufactured in the EU, ${ }^{32}$ and so even if registration was not required. A range of information must be submitted by the applicant for authorisation, including a chemical safety report (which may have already been required on registration), and an 'analysis of the alternatives, considering their risks and the technical and economic feasibility of substitution'; if 'suitable alternatives' are 'available', the application must include a 'substitution plan'. ${ }^{33}$ This initial step in the application for authorisation is very much in the hands of industry. Authorisation can be granted through two routes. Either the 'risk to human health or the environment' posed by the SVHC 'is adequately controlled', ${ }^{34}$ or, if authorisation cannot be granted under the 'adequate control' provision, authorisation can be granted 'if it is shown that socio-economic benefits outweigh the risk to human health or the environment arising from the use of the substance and if there are no suitable alternative substances or technologies'. ${ }^{35}$ Again, the applicant is likely to provide the 'first draft' of the 'socio-economic assessment' of chemicals.

\footnotetext{
30 E. Fisher, 'The 'Perfect Storm' of REACH: Charting Regulatory Controversy in the Age of Information, Sustainable Development and Globalization' (2008) 11 Journal of Risk Research 541; V. Heyvaert, 'Regulating Chemical Risk: REACH in a Global Governance Perspective' in J. Eriksson, M. Gilek and C. Rudén (eds.), Regulating Chemical Risks: European and Global Challenges (Dordrecht: Springer, 2010).

${ }^{31}$ Art 57.

32 Art 56.

${ }^{33}$ Art 62(4).

${ }^{34}$ Art 60(2). 'Adequate control' is another open ended standard, but means basically that particular 'safe' exposure levels are identified and not exceeded, and that the likelihood of an event such as an explosion is negligible, Art 60(2), Section 6.4 of Annex I.

35 Art 60(4).
} 


\section{The Demand for Economic Actor Enrolment}

Historically, regulation has been perceived as a largely state-centred activity, and for good reason. The state is expected to have (or have the wealth to generate, if necessary) the information needed to design an effective regulatory scheme; it possesses legal and normative legitimacy (by way of a democratic mandate); and has the organisational capacity to deal with complex problems. ${ }^{36}$ Complex governance arrangements at EU level, involving national as well as EU-level actors at all steps of the process, now increasingly play this 'state' role. But it is also recognised at all levels of governance that private (non-state and non-EU) actors, composed of economic actors and other 'civil actors' such as $\mathrm{NGOs}^{37}$ hold resources that, if harnessed appropriately, can make a valuable contribution to the regulatory process. The activity of governing is increasingly being shared with or devolved upon private interests: regulation has been 'decentred' from public institutions. ${ }^{38}$

There are numerous reasons for enrolling private actors in the regulatory process. ${ }^{39}$ One of the most commonly cited justifications is that of resource asymmetry. Industry, for example, may have access to current information and expertise that can be used to make sound and informed regulatory decisions. The inclusion of industry's information and expertise should improve the quality of decisions, which in turn may increase the chances of successful implementation, and reduce the need for 'extensive and inefficient monitoring and enforcement. ${ }^{40}$ This is not to say that public institutions have no expertise in the regulatory subject. But the state or the EU is unlikely to know as much about industrial operations as the industry itself. Economic actors may also have the financial and economic capacity to generate information and expertise where this is lacking, as for example in the obligation to carry out testing in certain circumstances under REACH. Private actors (environmental interest groups as well as industry) may also be in a better position than the EU or Member States institutions to disseminate that information, for example about standards, effectively and efficiently.

\footnotetext{
${ }^{36}$ See for example C. Hood, The Tools of Government (Basingstoke: Palgrave Macmillan, 1983) at 46.

37 The term civil actors embraces a broad range of groups and organisations including environmental and consumer groups, charities and foundations (see Hutter above $\mathrm{n} 2$ at 2).

${ }^{38}$ Black, above $\mathrm{n} 13$.

39 See for example, C. Scott, 'Private Regulation of the Public Sector: A Neglected Facet of Contemporary Governance' (2002) 29 Journal of Law and Society 56; J. Black, 'Enrolling Actors in Regulatory Systems: Examples from UK Financial Services Regulation' (2003) Public Law 63; C Abbot, 'Bridging the Gap - Non-state Actors and the Challenges of Regulating New Technology' (2012) 39 Journal of Law and Society 329.

40 D. Casey and C. Scott, 'The Crystallization of Regulatory Norms' (2011) 38 Journal of Law and Society 76 at 88.
} 
In similar vein, the participation of economic actors can potentially guard against the risk of 'regulatory disconnection', by which we mean the possibility that the regulatory controls, due to developments in, for example, science and technology, become disconnected from the regulatory target. ${ }^{41}$ Private actors occupy a strategic position in which they are able to keep abreast of scientific advances and technological development. Their evolving knowledge can inform decisions about whether and when regulation needs to be adapted to reflect such changes. Both IED and REACH attempt to govern highly technically complex and potentially fast moving areas in which regulatory disconnection is a real concern.

Cost effectiveness and efficiency are other important regulatory values, closely aligned with resource asymmetry, that might be enhanced by the enrolment of private, notably economic actors. In the absence of, in particular, industry's cooperation, information generation is likely to be very costly and could render the regulatory framework inefficient. ${ }^{42}$ The same may in some cases be said of the relative effectiveness and efficiency of different actors at other moments in the regulatory process: the diffusion of standards, monitoring and enforcement may benefit from the involvement of economic actors. ${ }^{43}$ In addition to concerns about overall social costs, there may be a concern simply to transfer costs away from the public sector. Of course, promoting private actor involvement in, say, standard-setting will not necessarily be less resource-intensive for the regulator than traditional rule-making, bearing in mind the setup costs involved in facilitating the negotiating process. ${ }^{44}$ But as Grabosky observes, 'a major challenge faced by democratic governments in the twenty-first century will be to achieve new efficiencies in the conduct of public affairs. One means of accomplishing this is to harness resources residing outside the public sector in furtherance of public policy.' ${ }^{45}$

The enrolment of private actors in the regulatory process may also have the potential to strengthen the legitimacy and accountability of regulation. As Freeman notes, '[p]rivate actors are not just rent-seekers that exacerbate the traditional democracy problem in administrative law; they are also regulatory resources capable of contributing to the efficacy and legitimacy of administration'. ${ }^{46}$ We turn to this in the next section.

\footnotetext{
${ }^{41}$ For a discussion of 'regulatory disconnection' see R. Brownsword, Rights, Regulation and the Technological Revolution (Oxford University Press, 2008).

${ }^{42}$ A. Ogus, 'Rethinking Self-Regulation' (1995) 15 Oxford Journal of Legal Studies 97.

${ }^{43}$ Ogus ibid.; C. Scott, 'Analysing Regulatory Space: Fragmented Resources and Institutional Design' (2001) Public Law 329.

44 J. Freeman, 'Collaborative Governance in the Administrative State' (1997) 45 UCLA Law Review 1.

${ }^{45}$ P. Grabosky, 'Using Non-Governmental Resources to Foster Regulatory Compliance' (1995) 8 Governance 527 at 527.

46 J. Freeman, 'Private Parties, Public Functions and the New Administrative Law (2000) 52 Administrative Law Review 813 at 819.
} 
In short, there are compelling reasons why private actors (including economic actors) can and should engage with and participate in the process of regulatory implementation. The functions they perform are varied. They may, themselves, constitute regulatory bodies: there are numerous examples of non-state regulators including, in the social and environmental context, accreditation bodies such as the FLOCERT (an independent subsidiary of Fairtrade International) and the Forest Stewardship Council. ${ }^{47}$ They may also make important contributions at all stages of the regulatory process. As is the case in $\mathrm{REACH}$, they can perform an information-generation role. Chemicals regulation is a good example of the limitations of relying solely on information generated by the public sector for regulatory purposes. By wide agreement, regulation was almost paralysed by a lack of information before the introduction of REACH. Under the earlier system, 'new' (post-1981) chemicals had to be notified by manufacturers or importers and tested; 'existing' chemicals, which in most cases had not been adequately tested when they were put on the market, were to be evaluated case by case. ${ }^{48}$ The onus to produce evidence to justify any restrictions imposed on the use of chemicals was entirely on the regulator. Between 1996 and 1998, only four existing chemicals went through full assessment. ${ }^{49}$ The 'no data, no market' approach in $\mathrm{REACH}$ is an important effort to remedy our ignorance of the qualities and impacts of chemicals. In the absence of regulation, there are disincentives on the private sector to engage in safety research. ${ }^{50}$

Private actors may also be involved in standard-setting or rule formation, as under the IED. In addition, private action may be crucial in fulfilling functions relating to monitoring and enforcement, including through action in the courts. These various roles may be vested in private actors by formal legal authority, but they may also have the capacity (information, wealth, organisation) to exert more informal authority that, for example, influences rule formation and enforcement processes. ${ }^{51}$

\section{Legitimacy and Accountability: the Tensions}

\footnotetext{
47 See J. Black, 'Constructing and Contesting Legitimacy and Accountability in Polycentric Regulatory Regimes' (2008) Regulation and Governance 137. The Forest Stewardship Council and FLOCERT are both now members of the ISEAL Alliance, a global membership association for sustainability standards (see A. Loconto and E. Fouilleux, 'Politics of Private Regulation: ISEAL and the Shaping of Transnational Sustainability Governance' (2014) 8 Regulation and Governance 166.

48 V. Heyvaert, 'The EU Chemicals Policy: Towards Inclusive Governance' LSE Law, Society and Economy Working Paper 7/2008.

${ }^{49}$ E.S. Williams, J. Panko and D.J. Paustenbach, 'The European Union's REACH Regulation: A Review of its History and Requirements' (2009) 39 Critical Reviews in Toxicology 553.

50 See for example, W. Wagner, 'Choosing Ignorance in the Manufacture of Toxic Products' (1997) 82 Cornell Law Review 773; L. McGoey, 'The Logic of Strategic Ignorance' (2012) 63 The British Journal of Sociology 553.

51 See for example, Scott, above n 39.
} 
At the heart of the concerns about the enrolment of economic actors are the two fundamental public law values of legitimacy and accountability. Whilst private actors can make regulation more effective and legitimate, they also raise a new set of challenges: 'Enrolment can expand capacity but simultaneously introduce critical vulnerabilities and distortions'. ${ }^{2}$ This section provides some elaboration of these concerns, and the next section considers how the IED and REACH respond to them.

In both of the examples discussed here, the primary contribution of economic actors (the focus of our study) is to provide highly technical specialist information. Nevertheless, we should put to one side any suggestion that the technical nature of the IED and REACH eliminates concerns about legitimacy and accountability. Few regulatory decisions are purely technical, in the sense that they involve 'objectively' correct and universally applicable answers that would be reached by any knowledgeable individual or group who considers the issue. There is self-evidently no single, 'correct' technical answer to what constitutes BAT. The BREF is a mixture of the evaluative and the factual, and the Commission recognises that identifying the 'best' technique is a matter of expert judgment, without any suggestion that this can be a purely technical exercise. ${ }^{53}$ Similarly, there is no single, 'correct' technical answer to, for example, the content of a safety data sheet under REACH. Technical assessments are pervaded by value judgments and professional assumptions, which are not necessarily self-serving, but which may consciously or unconsciously reflect the position and interests of participants. Moreover, these assumptions are often embedded in the technical assessment so that they remain unexamined and unchallenged. ${ }^{54}$ Decisions taken under both the IED and REACH involve choices and assumptions, and these choices and assumptions contribute to the overall level of environmental protection, the risks and costs borne by neighbours, consumers and others, and the costs borne by industry (which may be passed on to employees and consumers). The political nature of the decisions being taken under REACH and the IED mean that technical expertise, or an aspiration to technical objectivity, cannot in itself render a decision-making process legitimate.

'Legitimacy' and 'accountability' are closely connected and complex terms, and are the subjects of a vast literature, to which we do not intend to add; we are very specifically

\footnotetext{
52 J. Black, 'Paradoxes and Failures: 'New Governance' Techniques and the Financial Crisis' (2012) 75 Modern Law Review 1037 at 1056. See also Freeman, above n 46.

${ }^{53}$ European Commission, BREF on Economics and Cross-Media Effects (Luxembourg: European Commission, 2006).

${ }^{54}$ Expert Group on Science and Governance, Taking European Knowledge Society Seriously (Luxemburg: European Commission, 2007).
} 
concerned with the challenges thrown up by the unavoidability of economic actors in regulation. Accountability is concerned with the 'obligation to explain and justify conduct', ${ }^{55}$ describing a 'tool for citizens to force those vested with public power to speak the truth'. ${ }^{56}$ On most analyses, accountability requires some form of external scrutiny, and sometimes, associated consequences. ${ }^{57}$ Lawyers are accustomed to looking to courts for legal accountability, but the activities of economic actors may not be amenable to judicial review. Similarly, familiar forms of political (democratic) accountability do not necessarily extend to economic actors, since they are removed from the democratic process. ${ }^{58}$ This is not to say that economic actors cannot be held accountable through other means, which may go largely unrecognised in administrative law, such as market pressures, oversight by third parties such as media or NGOs, and more informal behavioural norms of compliance. ${ }^{59}$ One important role for law, and the three safeguards discussed in the next section, may be to enable those informal accountability mechanisms. ${ }^{60}$ But nevertheless, 'to the extent that they increasingly perform traditionally public functions unfettered by the scrutiny that normally accompanies the exercise of public power, private actors may indeed raise accountability concerns .... ${ }^{61}$

By legitimacy, we are essentially concerned with the acceptability of decisions to those affected by them, as well as the acceptability of the processes by which those decisions were reached; whether an institution is "perceived as having a "right to govern" both by those it seeks to govern and by those on whose behalf it purports to govern'. ${ }^{62}$ Whilst these two aspects of legitimacy are impossible to separate neatly, ${ }^{63}$ the EU literature commonly assesses legitimacy along the lines of 'input' legitimacy and 'output' legitimacy, relating respectively to the process by which a decision is reached, and the quality of a decision. ${ }^{64}$

55 M. Bovens, 'Analysing and Assessing Accountability: A Conceptual Framework' (2007) 13 European Law Journal 447 at 450.

56 M. Bovens, T. Schillemans and P. Hart, 'Does Public Accountability Work? An Assessment Tool' (2008) 86 Public Administration 225 at 225.

57 A. Benz, C. Harlow and Y. Papadopoulos, 'Introduction' (2007) 13 European Law Journal 441.

58 See C. Harlow, 'Composite Decision-making and Accountability Networks: Some Decisions from a Saga' (2013) 32 Yearbook of European Law 3, on the fragile survival of the 'classical accountability mechanism'. The same of course applies to other private actors such as NGOs.

59 Freeman, above $\mathrm{n} 46$.

60 N. Gunningham, 'Corporate Environmental Responsibility: Law and the Limits of Voluntarism' at 476-500 in D. McBarnet, A. Voiculescu and T. Campbell (eds.), The New Corporate Accountability: Corporate Social Responsibility and the Law (Cambridge University Press, 2007).

61 Freeman, above $\mathrm{n} 46$, at 828.

62 Black, above $\mathrm{n} 39$, at 76 .

${ }^{63}$ R. Bellamy, 'Democracy Without Democracy? Can the EU's Democratic "Outputs" be Separated from the Democratic "Inputs" Provided by Competitive Parties and Majority Rule?' (2010) 17 Journal of European Public Policy 2.

64 J.H.H. Weiler, 'In the Face of Crisis: Input Legitimacy, Output Legitimacy and the Political Messianism of European Integration' (2012) 34 European Integration 825. 
The particular interests of economic actors may generate concerns about the output of regulatory processes. The essential concern is that private standard-setting lacks rigour, the 'suspicion that [economic actors] may be biased towards weak standards which favour business'. ${ }^{65}$ Even those who resist public choice explanations tend to think of individual actors as playing quite a narrow and mainly rent-seeking role in decision-making. ${ }^{66}$ The identification of frequently 'indulgent' 67 regulation of the financial industry in the post mortem of the global financial crisis is salutary, and many of those involved in the Seville process do seem to perceive industry actors to be pursuing their own commercial interests. ${ }^{68}$ And in terms of 'input' legitimacy, the concern would be that a process dominated by the interests of economic actors would not be considered 'fair' to those with other perspectives.

The involvement of economic actors, on the other hand, can contribute to the enhancement of legitimacy and accountability. For example, economic actors can enhance accountability by providing expert, committed scrutiny of the input of other economic actors, as well as scrutiny of public regulators. The substantive quality of regulation is enormously important to perceived legitimacy, and one of the strengths of populating the regulatory space with economic actors (and private actors more generally) is, as mentioned above, that it should lead to more informed decision-making. This should in turn improve the substantive content of environmental regulation, although of course what counts as a 'good' decision is inevitably judged along many parameters, on which people are likely to disagree. ${ }^{69}$ Further, the involvement of industry in decision-making may particularly enhance the legitimacy of regulation for regulated parties, because they feel that their interests are being considered, or that outcomes are improved. But diverse 'legitimacy communities' will make different demands on governance mechanisms. ${ }^{70}$ For example, if, as suggested above, the involvement of industry may increase legitimacy in the eyes of the regulated, it may simultaneously reduce legitimacy in the eyes of environmental interest groups; ${ }^{71}$ acceptability to consumers or workers exposed to chemicals, or those living near major industrial facilities, is an additional complication. So there may be legitimacy trade-offs to be made.

\footnotetext{
${ }^{65}$ Hutter, above $\mathrm{n} 2$, at 13. For even more worrying possibilities of collusion see Freeman, above n 46 at 83.

66 Freeman, above $\mathrm{n} 46$.

67 Black, above $\mathrm{n} 52$.

68 Lange, above $\mathrm{n} 17$, at 108 . It is also possible that large organisations may seek to impose anticompetitive (possibly highly environmentally protective) standards that would disadvantage smaller businesses, or that industry already subject to high environmental standards will seek to impose those standards also on competitors.

69 Freeman, above $\mathrm{n} 44$ at 23-27.

70 Black, above $\mathrm{n} 47$.

${ }^{71}$ Black, above n 39.
} 
The complexity and dynamics of legitimacy and accountability mean that we can neither conclude in the abstract that the strong involvement of economic actors necessarily detracts from legitimacy, nor provide any simple prescription to enhance legitimacy. Legitimacy can be achieved in different ways, for example through legislative authority, regulatory expertise, accountability, and fairness, openness and participation. ${ }^{72}$ Institutions may seek to respond to the strongest of the dynamic and complex demands being made of them, compromising other demands. ${ }^{73}$ We can however conclude that an intimate role for economic actors in their own regulation raises questions of accountability and legitimacy that demand a response. Inclusion, transparency and public oversight and responsibility all speak to the values of legitimacy and accountability in some way, and these are the subjects of the next section.

\section{Responses}

The response to the challenges of information generation cannot be simply to turn away from economic actors, back to public authority. Massive investment in public resources, such as would enable the rejection of a strong role for economic actors in governance, is politically rather unlikely. More importantly, such a response would fail to capture the complexity of regulation, or indeed of society, which is clearly apparent in the regulation scholarship. Regulatory resources are fragmented and dispersed, whether we turn to ideas of de-centred regulation ${ }^{74}$ or the different concept of 'regulatory space', ${ }^{75}$ or the ideas of 'reflexive law' that are apparent in Schepel's discussion of the role of the private sector in standardisation. ${ }^{76}$ One of the challenges of responding to the involvement of economic actors in regulation is to avoid resurrecting the problems that led in the first place to a call on economic actors. More complex, and perhaps less satisfying, responses than a turn away from economic actors, need to be sought.

Without claiming to be exhaustive (other candidates for exploration include the duty to show 'due care' in decision making, ${ }^{77}$ reason-giving and 'good faith' obligations), we have identified in the IED and REACH three overlapping legal responses to the challenges posed

72 R. Baldwin, M. Cave and M. Lodge, Understanding Regulation: Theory, Strategy, and Practice (Oxford University Press, 2012), Chapter 5.

${ }^{73}$ See for example Black above n 47; H. Jarman, 'Collaboration and Consultation: Functional Representation in EU Stakeholder Dialogues' (2011) 33 Journal of European Integration 385.

${ }^{74}$ Black, above n 13.

75 Hancher and Moran, above n 13

${ }^{76}$ Schepel, above $\mathrm{n} 11$.

77 See P Craig, EU Administrative Law (Oxford University Press, 2012) at 333; Case C-269/90 Technische Universität München v Hauptzollamt München-Mitte [1991] ECR I-5469. 
by economic actor enrolment in regulatory implementation. Those three responses, discussed further below, are inclusion, transparency and public oversight and responsibility.

First, the inclusion of a range of public and private actors, with countervailing interests, may enhance the legitimacy of decisions, by improving the quality of a decision, and even by, as Freeman puts it, providing an 'independent, democracy-enhancing value'. ${ }^{78}$ Secondly, and closely related to inclusion, an emphasis on transparency should ensure the public availability of information (of various types, as discussed below). This can enhance accountability by allowing for broader scrutiny and challenge of regulatory inputs and outputs. And thirdly, public oversight and responsibility is thought to mitigate any concern about the legitimacy of the process. Public authorities, including regulators at EU or national level, may be enabled or required to contribute to the decision-making forum, and to scrutinise the industry's input into the process. In addition, passing ultimate responsibility for a final decision back to a public body attempts to sidestep the issues around the prior involvement of economic actors, relying on the familiar political and legal legitimacy and accountability of the final decision-making body. There are a number of difficulties with this, but for now we might simply note the strain implied in any effort to rationalise innovative governance mechanisms within a highly formal EU model of delegation and agency.

Each of these responses is important. We do not suggest that even in an ideal world they will be sufficient to eliminate concern about the enrolment of economic actors in EU environmental decision-making. However, constant attention to these 'building blocks' of legitimacy should be a minimum expectation for the design of governance frameworks. ${ }^{79}$ And studying the IED and REACH in this context illustrates three things. First, there is at least some level of legal consciousness of the importance of these safeguards. Secondly, these safeguards are potentially feasible and workable. And thirdly, as discussed in section $\mathrm{VI}$ below, the implementation of these safeguards could be much more consistent and effective than is currently the case.

\section{A. Safeguard 1: Inclusion}

Broad inclusion in processes of decision-making might be expected to enhance the legitimacy of the regulatory contributions of economic actors in a number of ways. It is moreover a core value that sits alongside, as well as sometimes in tension with, demands for

\footnotetext{
${ }^{78}$ Freeman, above $\mathrm{n} 46$ at 848.

${ }^{79}$ See de Burca, above $\mathrm{n} 4$ discussing, more ambitiously, the 'building blocks' of democracy.
} 
'expert' information and knowledge in EU environmental governance. ${ }^{80} \mathrm{~A}$ mix of public and private actors may help to introduce more diverse interests and values into the process, and enhance scrutiny to guard against overly onerous or lax standards. We return to public actors below. Broadening participation to include 'civil actors' 81 such as environmental or consumer interest groups, alongside economic actors, may provide different perspectives on the regulatory task, and may broaden the range of possible solutions. ${ }^{82}$ Civil actors can scrutinise and challenge information provided by economic actors, and provide competing technical information, as well as information on values and interests.

The ability of interest groups to 'represent' their members or citizens more generally can be problematic; members of environmental interest groups often do not, and may not wish to, shape the agenda of the NGO. ${ }^{83}$ Increased professionalisation of interest representation, in part to respond to the needs of EU regulation and of regulatory decentralisation, has further distanced groups from their members. ${ }^{84}$ So we are probably more concerned with the 'functional' representation of particular interests, in this case environmental interests.

Guaranteed opportunities for outsider (including environmental) input within the decisionmaking institutions are provided by both the IED and REACH. Recall that as defined in the IED, TWGs include 'Member States, the industries concerned, non-governmental organisations promoting environmental protection and the Commission'. Under REACH, the Commission can place up to six representatives (without voting rights) on the ECHA's Management Board (also made up of one 'representative' from each Member State), ${ }^{85}$ including three individuals from 'interested parties', currently a representative each from the chemicals industry and trade unions, and a law professor. ${ }^{86}$ The European Parliament can also appoint two 'independent persons', ${ }^{87}$ allowing for some parliamentary oversight. In addition, the Member State Committee, Risk Assessment Committee and Socio-Economic Assessment Committee of the ECHA all have stakeholder observers (including environmental groups) at their meetings, to which we return below.

\footnotetext{
80 Lee, above $\mathrm{n} 1$.

${ }^{81}$ See footnote 37 above and associated text.

${ }^{82}$ See J. Steele, 'Participation and Deliberation in Environmental Law: Exploring a Problem-solving Approach' (2001) 21 Oxford Journal of Legal Studies 415; Freeman, above n 44.

${ }^{83}$ A. Warleigh, 'Europeanising' Civil Society: NGOs as Agents of Political Socialisation (2001) 39 Journal of Common Market Studies 619.

84 W. Maloney, 'The Professionalization of Representation: Biasing Participation' in B. Kohler-Koch, D. de Bièvre and W. Maloney (eds.) Opening EU-Governance to Civil Society Gains and Challenges (Mannheim: CONNEX Report Series, 2008).

${ }^{85}$ Art 79.

${ }^{86}$ ECHA, General Report 2013 (Helsinki: ECHA, 2014).

87 Art 79.
} 
The challenge is to ensure that so far as possible no single grouping or set of interests dominates the regulatory process. Information we have received from the European IPPC Bureau, as discussed above, suggests much greater industry than environmental involvement. ${ }^{88}$ Koutalakis et al, in their case study of the implementation of the IED in Hungary, Poland, Romania and Greece, reveal that small and medium enterprises are generally underrepresented on TWGs. ${ }^{89}$ Member States are well represented in the TWGs, although in some cases, the Member State representative is an economic actor in the sector. For example BPEX, an organisation representing pig levy payers in England and Wales ${ }^{90}$ was a UK representative (along with the Environment Agency) in the TWG on the intensive rearing of poultry and pigs; and three industry members represented the UK, alongside the Environment Agency, on the Large Combustion Plants TWG.

It is difficult to interpret the limited data on who participates in TWGs. A comparison between the overall list of participants provided by the European IPPC Bureau and the summary in the minutes of those participating in the 'kick off meetings' ${ }^{91}$ demonstrates, as might be expected, that some participants do not attend. Apparently, neither of the two environmental NGOs participating in the TWG for the Intensive Rearing of Poultry and Pigs (the European Environment Bureau and the Danish Society for Conservation) attended the kick-off meeting. These kick-off meetings, the first plenary meeting of the TWG, are crucial in defining the scope of the BREF review and include agreement on the data to be collected. ${ }^{92}$ The potential absence of environmental representation at this stage could therefore prove highly significant. The European IPPC Bureau does not reveal how many individuals each represented organisation sent to TWG meetings. The minutes for the kick off meeting for the Large Combustion Plants BREF states that the TWG was composed of 'more than 140 experts', of whom 'more than 90' attended the kick off meeting; the list of participant organisations provided to us by the European IPPC Bureau contains 102 institutions, so presumably some were represented by more than one expert. ${ }^{93}$ Nor is the seniority, expertise or experience of the individual participants apparent. But even if incomplete, and in any event a crude measure of legitimacy, the data on participation in TWGs is sufficient to raise some concern about the role of industry.

\footnotetext{
88 Text at $\mathrm{n} 21$.

${ }^{89}$ C. Koutalakis, A. Buzogany and T. Börzel, 'When Soft Regulation is Not Enough: The Integrated Pollution Prevention and Control Directive of the European Union' (2010) 4 Regulation and Governance 329.

90 See www.bpex.org.uk

${ }^{91}$ Minutes are available at http://eippcb.jrc.ec.europa.eu/reference/

${ }_{92}$ Commission Implementing Decision 2012/119/EU above $\mathrm{n} 24$.

${ }^{93}$ The minutes of the Kick off meetings do not provide standardised information.
} 
We should also note that the IED provides no right for anyone in particular to participate in the drafting of BREFs. Whether representing environmental or industry interests, participants have to be nominated to TWGs. The environmental interest is plural, and perspectives on particular environmental issues will vary depending on factors such as underlying ideology as well as whether one is concerned with local or global issues. ${ }^{94}$ There is an obvious concern that the identification of stakeholders will exclude groups with challenging ecological viewpoints, and, notwithstanding the Commission's acknowledgement of the value of those not focused on EU issues, ${ }^{95}$ it is clear that the Commission prefers to work with panEuropean organisations. ${ }^{96}$

In relation to the regulation of chemicals under $\mathrm{REACH}$, the $E C H A$ says that its stakeholders, namely 'all individuals interested in or affected by' chemicals regulation, are welcome at various events, including an 'annual stakeholders day'. 97 Recognised stakeholder organisations must be non-profit making and work at an EU level, have a 'legitimate interest' in the work of the ECHA, and be representative of their field of competence. ${ }^{98}$ They are able to participate in committees, and other activities such as the preparation of guidance. There does seem, quantitatively, to be a more even representation of different interests, at least at the level of accreditation, than in Seville. ${ }^{99}$ Further, the Committee meeting minutes list stakeholder observers, by name and affiliation. So for example, the Risk Assessment Committee of 2-6 June 2014 was attended by stakeholder observers from the European Chemical Industry Council, the European Trade Union Confederation, ClientEarth (a legal environmental NGO), CONCAWE (a science body formed by the oil industry) the European Environment Bureau, the European Crop Protection Association and the European Association of Metals. In addition five 'industry experts' attended the meeting, extending industry representation. ${ }^{100}$ The Committees, recall, are provided initially with information from the importer or manufacturer of the chemical at issue. The ECHA considers stakeholder involvement to be a 'positive' experience, which 'helps

94 For example, see G. Smith, Deliberative Democracy and the Environment (London: Routledge, 2003).

95 European Commission, Towards a Reinforced Culture of Consultation and Dialogue - General Principles and Minimum Standards for Consultation of Interested parties by the Commission, COM (2002) 704 final.

96 See for example, Commission Decision establishing a forum for the exchange of information pursuant to Article 13 of the Directive 2010/75/EU on industrial emissions [2011] OJ C 146/3 at Article 4.

97 See http://echa.europa.eu/about-us/partners-and-networks/stakeholders

${ }^{98} \mathrm{ECHA}$, ECHA's approach to engagement with its Accredited Stakeholder Organisations, (Helsinki: ECHA, 2011).

${ }_{99}$ See http://echa.europa.eu/documents/10162/13579/rac loa sto en.pdf

100 See http://echa.europa.eu/documents/10162/13579/rac 29 minutes en.pdf for details. 
guarantee the credibility and transparency of the decision-making process'. ${ }^{101}$ Some concern has however been expressed by others about the ECHA's 'strong engagement with industry stakeholders'. ${ }^{102}$

The quantitative overrepresentation of economic interests, by comparison with collective interests, seems to be relatively common. But it is difficult to draw firm or generalisable conclusions about the access of environmental interests to EU decision-making, let alone their influence. A significant literature on interest groups in the EU suggests that precise relationships of influence are difficult to measure ${ }^{103}$ and highly variable, depending, amongst other factors, on institutional (Parliament, Commission, etc) and functional (trade, social, environmental) contexts. ${ }^{104}$ Much of the literature is most concerned with the high politics of legislative processes, whilst for current purposes we are more interested in the routine implementation of legislation. ${ }^{105}$ Nevertheless, it is interesting to note that whilst industry and the larger Member States were quantitatively better represented during the open online consultation over $\mathrm{REACH},{ }^{106}$ qualitative research suggests that both environmental and industrial interest groups were happy with the process; industry only slightly happier; and that whilst industry had advantages over environmental interest groups in terms of influence, industry was not allowed to dominate. ${ }^{107}$ High levels of participation in the drafting of this enormously contentious piece of legislation ${ }^{108}$ may moreover support the claim that complying with a legislative framework enhances the perceived legitimacy of regulatory frameworks.

$101 \mathrm{ECHA}$, above n 98, 62.

102 See European Commission, General Report on REACH, COM (2013) 49 final at paragraph 4. See also C. Ossege, 'Is Expertise the Driving Force? Explaining Agency Autonomy in the EU' in C. Holst (ed.), Expertise and Democracy (2014, ARENA Report No 1/14) for a discussion of the ECHA and other agencies.

103 See for example T. Long and L. Lorinczi, 'NGOs as Gatekeepers: A Green Vision' in D. Coen and J. Richardson (eds.) Lobbying in the European Union: Institutions, Actors and Issues (Oxford University Press, 2009).

${ }^{104}$ See for example, A. Dur and D. de Bièvre, 'The Question of Interest Group Influence (2007) 27 Journal of Public Policy 1; M.P. Smith, 'All Access Points are not Created Equal: Explaining the Fate of Diffuse Interests in the EU' (2008) British Journal of Politics and International Relations 64; K-O Lindgren and T. Persson, Participatory Governance in the EU: Enhancing or Endangering Democracy and Efficiency? (Basingstoke: Palgrave MacMillan, 2011)

105 For example, it would appear that many NGOs diverted their limited resources away from chemicals to other priorities once the regulation had been passed. See O. Fuchs, REACH: A New Paradigm for the Management of Chemical Risks (Health and Environment Reports No 4 (IFRI, 2009). 106 T. Persson, 'Democratizing European Chemicals Policy: Lessons from the Open Consultation on REACH' Paper Prepared for the Workshop on the 'Institutional Shaping of EU-Society Relations' (2009).

107 Lindgren and Persson, above n 104.

108 Fisher, above n 30. 
Broader, possibly less formal, opportunities to contribute to, or at least scrutinise, regulatory processes provide a potentially important opportunity to correct for the selectiveness of institutional inclusion. Under the IED, opportunities for more general public participation arise later in the process, during the actual permitting of facilities. The IED provides that the 'public concerned' (explicitly including environmental interest groups) must be given 'early and effective opportunities to participate' in permitting procedures; information on the results of consultation, and an explanation of how those results were taken into account, must be provided. ${ }^{109}$ However, the capacity for local participation to feed into the legitimacy of BREF drafting is limited. Whilst regulatory judgment at the local level remains crucial, ${ }^{110}$ the prior determination of BAT at EU level limits the scope of the contributions that might be made by the public. This emphasises the need for earlier opportunities for outsiders to participate; as discussed in the next section, these are weak.

Under REACH, there are some opportunities for public contributions on the identification of SVHCs, on applications for authorisation, and on restrictions. In respect of authorisation, for example, the ECHA makes available on its website 'broad information on uses', and the ECHA's risk assessment and socio-economic assessment committees have to take into account' information submitted by third parties. ${ }^{111}$ The scope of public involvement in REACH is, however, strikingly limited. ${ }^{112}$ So on authorisation, third parties are only explicitly invited to provide information on 'alternative substances or technologies', rather than on broader issues. ${ }^{113}$ Similarly, when the ECHA evaluates registrants' testing proposals, interested parties are invited to make comments. Only comments on proposals that include animal testing, and even then, only 'scientifically valid information and studies', rather than ethical concerns, must be taken into account. ${ }^{114}$

\section{B. Safeguard 2: Transparency}

A routine response to the intimate involvement of economic actors in environmental governance is a call for transparency, so that we know who is contributing and what is being contributed to the process. Transparency is complicated: we are likely to disagree on precisely what should be made transparent; achieving transparency is not as easy as it

\footnotetext{
109 Art 24.

110 M. Lee, 'The Ambiguity of Multi-Level Governance and (De)-harmonisation in EU Environmental Law' (2014) Cambridge Yearbook of European Legal Studies 357.

111 Art 64(3).

112 Lee, above $\mathrm{n} 1$.

${ }_{113}$ Art 64(2).

114 Art 40(2).
} 
sounds; and transparency may not have the desired effect. ${ }^{115}$ But it is the crucial starting point for any form of legal accountability, or political debate, and the potential for scrutiny may encourage economic actors to be more open-handed with information. ${ }^{116}$ Whilst it is not the focus here, the regulatory potential of information at subsequent stages of governance (especially implementation and enforcement) should also be borne in mind.

Under the IED, some drafts of BREFs, prior to agreement by the TWG, are published, although, importantly, this is not required by the Directive; the Forum's Opinion is also published. However, beyond the provision of the European IPPC Bureau's contact details, there is no mechanism by which the comments of those not participating in the TWG will be fed into the process, for example no obligation to respond to comments, or to explain how comments have been taken into account. The absence of this sort of 'notice and comment' procedure, a common feature of law and policy making in other environmental contexts, undoubtedly weakens the legitimising value of transparency. Much of the information provided on registration under $\mathrm{REACH}$ is also made public, so that consumer groups, trade unions and environmental groups have opportunities for scrutiny. Competitors may also have an interest in scrutiny; they may have promising alternatives, or may want to compete on safety, or may simply be interested in the reputation of the sector. ${ }^{117}$ Both the European IPPC Bureau and the ECHA are subject to the EU's Access to Documents Regulation, ${ }^{118}$ as supplemented with respect to 'environmental information' by the Aarhus Regulation. ${ }^{119}$ This provides broad rights of access to information, subject to important exceptions. The withholding of information that would undermine somebody's commercial interests will require careful scrutiny under $\mathrm{REACH} .{ }^{120}$

References to transparency pervade both the Commission Implementing Decision on drawing up BREFs, ${ }^{121}$ and the cross-cutting BREF on economics and cross-media effects. ${ }^{122}$

\footnotetext{
${ }^{115}$ E. Fisher, 'Transparency and Administrative Law: A Critical Evaluation' (2010) 63 Current Legal Problems 272; S. Jasanoff, 'Transparency in Public Science: Purposes, Reasons, Limits' (2006) 69 Law and Contemporary Problems 21.

${ }^{116}$ Scott, above n 1515.

117 lbid.

118 Regulation 1049/2001/EC regarding public access to European Parliament, Council and Commission documents [2001] OJ L145/43

119 Regulation 1367/2006/EC on the application of the provisions of the Aarhus Convention on access to information, public participation in decision-making and access to justice in environmental matters to Community institutions and bodies [2006] OJ L264/13.

120 M. Bronckers and Y. van Gerven, 'Legal Remedies under the EC's New Chemicals Legislation REACH: Testing a New Model of European Governance' (2009) 46 Common Market Law Review 1823.

121 Commission Implementing Decision 2012/119/EC, above n 24.

122 European Commission, BREF on Economics and Cross-Media Effects (Luxembourg: European Commission, 2006).
} 
Transparency on the way in which BREFs are decided involves openness on the assumptions and the uncertainties embedded in the BREFs. The 'key purpose' of the detailed BREF methodologies, for example, is to ensure transparency, 'so that any part of the process can be validated or audited'. ${ }^{123}$ This should in turn enable political decisionmakers and outside observers to exercise their own judgment. The legitimacy of expert judgments (whoever our experts might be) rests at least in part on the ability of those experts to explain their conclusions in an understandable way. ${ }^{124}$ But equally, transparency in BREFs is directed less towards outsiders than towards those drawing up BAT Conclusions: the members of the TWG and the forum, the comitology committee and national regulators. This is not in itself problematic. The demands that a transparency approach to legitimacy makes on scrutineers should not be underestimated, ${ }^{125}$ and the more technical and complex the topic, the greater are the demands on the party doing the holding to account. So 'insiders' might be well equipped to hold others in the process to account. But accountees also need to be detached enough to question the methods and assumptions underlying information provided and conclusions drawn. ${ }^{126}$ The sort of expert accountability fostered by institutional inclusion of diverse interests under the IED and REACH is important, but is especially prone to the risk that the elite participants will develop shared interests that blunt accountability. ${ }^{127}$

Given what has been said about the significance of diverse participation in regulation, knowing who contributes to decisions is another important element of transparency. In other contexts, the Commission accepts the need to see 'which interests [participants] represent' and 'how inclusive that representation is'; 'who is being consulted and why'. ${ }^{128}$ The legislation, however, does not demand information to be provided on who participates in TWGs, or in ECHA committees. Institutional concern about complying with data protection rules ${ }^{129}$ has the potential to amplify the challenges of using economic actors in EU environmental law: for example, because of concerns about data protection, information on membership of TWGs, which used to be made routinely available on the website, is now only available on request. More information is made available on the ECHA website with

\footnotetext{
123 Ibid at iii.

${ }^{124}$ For a discussion of democracy and public reason see A. Moore, 'Democratic Theory and Expertise: Between Competence and Consent' in Holst, above n 102.

125 See G. de Búrca, 'New Governance and Experimentalism: An Introduction' (2010) Wisconsin Law Review 227-238; J. Black, 'Calling Regulators to Account: Challenges, Capacities and Prospects' LSE: Law, Society and Economy Working Papers 15/2012; Fisher above n 115.

126 Jasanoff, above n 115.

${ }^{127}$ C. Harlow and R. Rawlings, 'Promoting Accountability in Multilevel Governance: A Network Approach' (2007) 13 European Law Journal 542.

${ }^{128}$ European Commission 2002 above $\mathrm{n} 95$ at 17.

129 Regulation 45/2001/EC on the protection of individuals with regard to the processing of personal data by the Community institutions and bodies and on the free movement of such data OJ [2001] L $8 / 1$.
} 
respect to 'stakeholders', as discussed above. Members of the Risk Assessment and Socioeconomic Assessment Committees are also listed on the website, along with CVs and declarations of interest. Most of the members seem to be employed by national regulators, or as researchers or academics. The different approaches being taken by the different EU bodies is surprising, and demonstrates at a very basic level, the contested nature of legitimacy and accountability as due process values in decision-making, as well as apparently different views on what is required by data protection.

The legal position on data protection is certainly not straightforward. Bavarian Lager ${ }^{130}$ involved an investigation by the Commission into UK laws that allowed publicans to be 'tied' into an exclusive purchasing agreement with breweries. In this well-known case, Bavarian Lager challenged the removal from a document of the names of those participating in a relevant meeting. Sharpston $A G$ argued that 'the context (an official meeting involving representatives of an industrial group acting as spokesmen for their employers, and thus purely in a professional capacity) taken together with the principle of transparency, provided ample justification' for release of this information. ${ }^{131}$ This powerful argument was not accepted by the Court, which held that the redaction of the names was lawful. In its subsequent decision in Volker, ${ }^{132}$ however, the Court emphasised the need to strike a balance between public interests in transparency and the protection of personal data, with no automatic priority for either: 'The right to the protection of personal data is not ... an absolute right, but must be considered in relation to its function in society', and applied 'only in so far as is strictly necessary'. But a subsequent ClientEarth decision suggests that Volker will be difficult to satisfy: those requesting access to information subject to data protection requirements must establish the necessity of the transfer of that data on public interest grounds; but general public interests in transparency are not sufficient to establish necessity. ${ }^{133}$

\section{Safeguard 3: Public Oversight and Responsibility}

An insistence on public responsibility for decisions can be powerful, and is arguably the most explicit way of trying to avoid concerns about the identity and interests of those who contribute to the decision. First of all, this safeguard is about a supervisory, scrutinising role

\footnotetext{
130 C-28/08 P European Commission v Bavarian Lager [2010] ECR I-6055.

131 lbid at [192].

132 Joined Cases C-92/09 and C-93/09 Volker and Schecke, Eifert v Land Hessen [2010] ECR I11063. For discussion, see M. Bobek, Case Note (2011) 48 Common Market Law Review 2005 2022.

${ }^{133}$ Case T-214/11 ClientEarth and Pesticides Action Network v European Food Safety Authority, 13 September 2013, not yet reported in the ECR.
} 
for public authorities. The importance of the regulated industry in governing for environmental protection should not blind us to the continued and serious need for substantial public resources. ${ }^{134}$ As we suggested of environmental interest groups, regulators could provide expert and engaged accountees in these complex governance frameworks. But we should recall the advantages of economic actors over regulators are precisely in their privileged access to information and expertise.

The ECHA plays the primary public scrutiny role in REACH. The quality of registrations (and ECHA's scrutinising role) has been criticised. ${ }^{135}$ When substances are registered, the ECHA is responsible for 'dossier evaluation', which involves the evaluation of all testing proposals (the registrant of substances imported or manufactured in annual quantities over 100 tonnes, if all necessary information is not available, has to submit proposals for testing), plus a compliance evaluation of at least $5 \%$ of dossiers submitted. ${ }^{136}$ The ECHA (and its committees) also produce opinions in respect of authorisation, providing scrutiny of industry's submissions. The European IPPC Bureau also plays a potentially important, although less direct, role in the drawing up of BREFs. It 'coordinates', 'leads' and 'steers' the work carried out by the TWGs. ${ }^{137}$ It seeks information from members of the TWG, and presents formal and informal drafts to the TWG for comment. ${ }^{138}$ The EU's system of multilevel governance also complicates matters a little, since Member State representatives are members of TWGs; and although they are to act independently of their Member States, ${ }^{139}$ most members of the ECHA committees are essentially national regulators. But of course whilst Member States might have a distinct regulatory interest, at other times they may share the interests of a powerful industry. ${ }^{140}$

In addition to this scrutinising role, which overlaps with questions of inclusion and transparency discussed above, we often see an insistence that the final decision is taken by a public authority, or that standards not so adopted are merely voluntary. National regulators, for example, negotiate and apply the final permit in IED. Perhaps more significantly for current purposes, the EU Courts ${ }^{141}$ frequently insist that final responsibility for a decision

\footnotetext{
${ }^{134} \mathrm{C}$. Ford, 'New Governance in the Teeth of Human Frailty: Lessons from Financial Regulation' (2010) Wisconsin Law Review 441; Black, above n 125.

${ }^{135} \mathrm{EEB}$ and ClientEarth (2012) Identifying the Bottlenecks in REACH Implementation: The Role of ECHA in REACH's Failed Implementation http://www.eeb.org/EEB/?LinkServID=53B19853-5056B741-DB6B33B4D1318340. See also Ossege above $\mathrm{n} 102$.

136 Arts $40,41$.

137 European Commission, above n 24, 4.5.

$138 \mathrm{lbid}, 10-11$.

${ }^{139}$ Apart from the Member State Committee, which plays a more clearly political role.

140 Lange, above $\mathrm{n} 17$.

${ }^{141}$ For example Pfizer: Case T-13/99 Pfizer Animal Health SA v Council [2002] ECR II-3305.
} 
based on technically complex inputs is placed in the hands, not just of a public body, but of a political body. This is in some respects an effort to maintain what might be a formalistic myth that power has not been delegated to experts, but remains with the politically responsible body. But it is not entirely meaningless, and does potentially allow for political input into these decisions. Most commonly, including under the IED and REACH, the political body taking the final decision is the Commission, plus comitology. It applies to a range of decisions under $\mathrm{REACH}$, including final authorisation decisions. ${ }^{142}$ BAT Conclusions, the most significant and authoritative part of the BREFs, are ultimately adopted by the Commission, with comitology, reflecting the harder status of the BAT Conclusions under that legislation than previously. ${ }^{143}$

Comitology is a process that evolved to allow the Member States to supervise (in committee) the Commission's exercise of its implementing powers; it has evolved also into a forum for multi-level collaboration in decision-making. ${ }^{144}$ We can avoid some of the complexities of comitology, and the diversity of the processes, for current purposes. Broadly, under the Comitology Regulation, ${ }^{145}$ the Commission puts a draft decision to an 'examination committee', made up of 'representatives of the Member States' and chaired by a (non-voting) member of the Commission. ${ }^{146}$ 'Any committee member' may 'suggest amendments', and the Commission can present amended drafts at any point. Opportunities for negotiation, collaboration and consensus are emphasised. The committee can provide a positive or negative opinion on the Commission's draft, by qualified majority voting. In the vast majority of cases, comitology committees simply agree with the Commission, and the measure is adopted. ${ }^{147}$ If the examination committee rejects the draft, the Commission cannot adopt it; although if a rejected act is 'necessary', the Commission can either submit an amended draft to the committee, or submit the original draft to the Appeal Committee. If the examination committee does not reach an opinion in either direction, then in most environmental cases, the draft must be put before the Appeal Committee. As with the examination committee, members of the Appeal Committee can propose amendments, and the Commission has to seek wide support and explain its response to suggestions. The Appeal Committee can

\footnotetext{
142 Art 64

143 Lee, above $\mathrm{n} 1$.

${ }^{144}$ See for example C. Joerges and E. Vos (eds.) EU Committees: Social Regulation, Law and Politics (Oxford: Hart Publishing, 1999); P. Craig, 'Delegated Acts, Implementing Acts and the New Comitology Regulation' (2011) 36 European Law Review 671; R. Schutze, ' "Delegated Legislation" in the (new) European Union: A Constitutional Analysis' (2011) 74 Modern Law Review 661.

145 Regulation 182/2011/EU laying down the rules and general principles concerning mechanisms for control by Member States of the Commission's exercise of implementing powers [2011] OJ L55/13.

146 Art 5.

147 See for example, E. Vos, '50 Years of European Integration, 45 Years of Comitology' (2009) Maastricht Faculty of Law Working Papers 2009-3.
} 
adopt or reject a draft by qualified majority. If there is a positive opinion, the Commission 'shall' adopt its draft; if there is a negative opinion, it 'shall not adopt' it. If there is no opinion, the Commission 'may adopt' its draft.

The separation of technical expertise from political judgment, of facts from values, is not as clear-cut as is suggested by the institutional division between the responsibilities of Seville / the ECHA and the responsibilities of the Commission and Member States in committee: both the political and the technical inputs into a decision imply ethical commitments and matters of substance, values and facts. ${ }^{148}$ Nevertheless, for current purposes, the comitology process is supposed to provide a politically legitimate EU administrative standard. Whether it can really do so is open to question. Comitology has the potential to connect Commission decisions with national (and potentially democratic) concerns. Joerges and Neyer argue that comitology provides legitimacy by creating mechanisms for 'deliberative supranationalism', resting on 'good arguments', formulated in terms of the (EU-wide) public interest, rather than negotiation around positions of (national) self-interest. ${ }^{149}$ Whether committees actually do deliberate (rather than bargain from self-interested positions) is contested. The examination committees are composed of national experts who share a common professional understanding of the problem, and these sorts of bodies have well-observed tendencies to remain ignorant of alternative, less technical, perspectives on the problem. Nor are comitology committees, other than in unusual high profile and contested cases (such as around GMOs, or more recently neonicitinoids ${ }^{150}$ ) generally exposed to public scrutiny. The European Parliament does not have a direct role in comitology, but like the Council, it enjoys a 'right of scrutiny', a power to 'at any time indicate to the Commission' that they are of the view that a draft exceeds the implementing powers. This is a relatively weak power, since the Commission is obliged merely to 'review' the draft 'taking account of the positions expressed', and then inform the institutions 'whether it intends to maintain, amend or withdraw the draft implementing act'. ${ }^{151}$ However, it does allow political attention to be drawn to controversial acts.

The relatively weak political legitimacy of comitology means that it provides a less than full response to anxiety about a decentralised approach to regulation, any more than to concerns about the delegation of political discretion to technical bodies including economic actors. Even if the political legitimacy of comitology were more robust, outcomes agreed

148 See, for example, Expert Group on Science and Governance, above n 54.

149 C. Joerges and J Neyer, 'From Intergovernmental Bargaining to Deliberative Process: The Constitutionalisation of Comitology' (1997) 3 European Law Journal 273. See also Vos, above n 147.

150 Lee, above n 1, Chapter 2.

151 Art 11. 
collaboratively with economic actors may be preferred by EU and national actors. The Commission and Member States may, for example, prioritise successful implementation, seek to avoid litigation, or be so wedded to success of the collaborative governance process that they follow the recommendations of bodies incorporating economic interests more than they otherwise might. ${ }^{152}$ And it may in any event be difficult to exercise independent judgment in the face of a lengthy, complex and possibly inscrutable technical judgment. The point is that allocating ultimate responsibility to a political process does not guarantee legitimacy or accountability. This is not just a problem for the supranational context of the $\mathrm{EU}$; it is a challenge for administrative decision-makers in all jurisdictions. And it serves to re-emphasise the necessary focus on legitimacy and accountability at all stages of the earlier process.

\section{Strengthening Inclusion, Transparency and Public Oversight}

Our discussion so far suggests that EU law has developed some important mechanisms through which the inclusion of economic actors might tend to enhance rather than detract from the legitimacy and accountability of governance. However, our case studies reveal that the implementation of these safeguards could be much more consistent and effective than is currently the case. In this section we outline the limitations of the attempts in the IED and $\mathrm{REACH}$ to address some of these concerns, and suggest three (non-exhaustive) ways in which inclusion, transparency and public oversight could potentially be strengthened

Complete solutions are unavailable. The two most obvious overarching 'solutions' are probably either to include competing interests in decision-making processes on an equal basis with economic actors, or to pass final decisions to politically legitimate decision-makers. The former is crucial, but as explored further in this section, even-handed interest representation may often be impossibly difficult; similarly, as suggested in the previous section, the latter is important, but a fragile guarantor of legitimacy. And so we make three suggestions: consistent benchmarks should be developed for the reception of outsider contributions within decision-making processes; the identity or (at least) affiliation of those participating in a decision-making process should be publicly available; regulatory, or public regarding, scrutiny of the contributions of economic actors should be strengthened. These are deceptively modest suggestions, which build directly on the safeguards already routine in EU environmental law. Their implementation would be far from straightforward, however,

152 Freeman, above $\mathrm{n} 46$. 
as discussed below; but then nor is the involvement of economic actors in environmental decision-making a straightforward question.

Our emphasis on consistency may seem to speak for the desirability of something along the lines of a 'general administrative law' for the EU, ${ }^{153}$ as well perhaps as an extension of tools such as regulatory impact assessment to this sort of administrative decision-making. Some common expectations for governance, across the plethora of different bodies and arrangements operating across EU administration, ${ }^{154}$ may well be necessary. But this is not a simple technical question. ${ }^{155}$ There will be difficult trade-offs, for example between flexibility and context-sensitivity, over uniformity and rigidity. Moreover, the precise content and detail of any such law is really what matters: very weak minimum requirements may function to reinforce inadequate standards; unduly onerous requirements could restrict the potential for regulatory action; ${ }^{156}$ and the possibility that legally binding standards would be used by industry to delay and weaken legislation needs attention. Even in the absence of such a development, and even for those who consider such a development undesirable, however, there is certainly an important role for law in enhancing the three key safeguards that we have identified for public-regarding governance in the EU. Legislatures and the judiciary are able to '[signal] the benchmarks for normative activity' by requiring that thought be paid to these criteria. ${ }^{157}$

Starting with inclusion, as discussed above, both the IED and REACH provide illuminating examples of how the regulatory process attempts to guard against the dominance of a particular grouping by promoting the broad inclusion of a diverse range of interests in decision-making. Whilst recognising the difficulties inherent in drawing generalisable

${ }^{153}$ European Parliament, Resolution of 15 January 2013 with recommendations to the Commission on a Law of Administrative Procedure of the EU; European Commission, Follow up to the European Parliament resolution with recommendations to the Commission on a Law of Administrative Procedure of the European Union 24 April 2013 welcomes the recommendation and promises to undertake 'a detailed stocktaking exercise'. See also the ReNEUAL Model Rules on EU Administrative Procedure, www.reneual.eu (last accessed November 2014).

${ }^{154}$ The discussion of Seville and the ECHA committees here gives a hint of the diversity at EU level; for discussion of the possibility of a general administrative law that would apply to the national administration of EU policy, see P. Craig, 'A General Law on Administrative Procedure, Legislative Competence and Judicial Competence' (2013) 19 European Public Law 503

155 D. Curtin, H. Hofmann and J. Mendes, 'Constitutionalising EU Executive Rule-Making Procedures: A Research Agenda' (2013) 19 European Law Journal 1 discuss the constitutional implications of procedural choices.

${ }_{156}$ For example certain approaches to costs benefit analysis could limit the potential to take action where the costs of regulation are well understood and immediate, but benefits are difficult to calculate and distant in time. See the discussion of CBA under regulatory impact assessment in Lee, above $\mathrm{n} 1$, Chapter 2.

$157 \mathrm{~J}$. Scott and S. Sturm, 'Courts as Catalysts: Rethinking the Judicial Role in New Governance' (2007) 13 Columbia Journal of European Law 565. 
conclusions, our findings would suggest that despite guaranteed opportunities that promote outsider input, economic interests are likely over-represented. The classic literature on collective action predicts that diffuse interests (such as environmental protection) find it more difficult to organise than focused interests, such as economic interests. ${ }^{158}$ Environmental interest groups (as civil actors) do face clear weaknesses relative to industry, even once they have been included in the process. ${ }^{159}$ Whilst the EU's diffuse and under-resourced decision-making processes may have created opportunities for environmental NGOs, ${ }^{160}$ environmental interest groups generally have fewer resources than economic actors, and participation can be costly and time consuming. ${ }^{161}$ Public funding may enhance the capacity of environmental NGOs, but leads to obvious concerns, for example as to independence and advocacy. Environmental groups may also have less ready access to the information most valued by decision-makers. Their possibly greater resources of legitimacy may compensate to some degree, especially if they are able to demonstrate strong connections to European 'publics' (although the possibly limited connections with grassroots was raised above). The requirement to be able to work in English, without translation services, in order to participate in TWGs is a further barrier to inclusion; the ECHA's working language is also English, and whilst there is an effort to translate, some of the information on the ECHA website is published only in English.

Perhaps there is a sense of inevitability in this discussion of the weaknesses of NGOs relative to industry. But civil actors such as environmental interest groups are not powerless, and their inclusion in IED and REACH decision-making, alongside industry, is an important expansion of the perspectives addressed in decision-making. But some self-conscious reflection on the burden that can reasonably be borne by environmental interest groups is necessary. Formal equality between environmental interest groups and economic actors must not distract from the very significant inequalities in practice, and it should not be assumed that because an environmental group was in the room, interest representation was even-handed. This leads to two of the suggestions in this section: first, that a crucial role in the identification and protection of public interests remains for regulators; and secondly, the need for clarity in every case on precisely who is participating in a decision-making forum.

\footnotetext{
158 M. Olson, The Logic of Collective Action: Public Goods and the Theory of Groups (Harvard University Press, 1965).

159 Lindgren and Persson, above n 104.

160 Long and Lorinczi, above n 103.

161 On Technical Working Groups see C. Koutalakis, Regulatory Effects of Participatory Environmental Networks: The case of the 'Seville Process' (2005) http://www.eunewgov.org/datalists/deliverables detail.asp?Project ID $=14$.
} 
One less direct response to the need to correct the selectiveness of institutional inclusion may be to provide for broader, possibly less formal, opportunities to contribute to, or at least scrutinise, regulatory processes. Such opportunities could enhance both input and output legitimacy. As discussed above, there are possibilities for outsiders to scrutinise certain documents under the IED and REACH. But recall also the absence of any clear mechanisms by which comments will be fed into the process under the IED. This contrasts with the arrangements made for contributions from members of the TWG, in which case there must be a 'commenting period of at least eight weeks', and 'detailed feedback' is required from the European IPPC Bureau 'on how their major comments have been taken into account'. ${ }^{162}$ In short, accountability mechanisms towards insiders to the process are strong; less so externally. And under REACH, the moment at which and topics on which information is sought from outsiders are deliberately limited. Perhaps then, there is space for a more expansive role to be played by third parties who are not privileged by virtue of explicit inclusion in the regulatory decision-making process.

There are of course costs to increasing the diversity of participation in decision-making, most obviously increased transaction costs, reduced speed, the legitimacy trade offs mentioned above, even possibly associated trade offs in the reaching of other regulatory objectives. Nor are we suggesting that consensus should (or could) be the objective of participation; dissent will continue. But some very simple things are absent or unpredictable in our case studies: wide and early availability of drafts, clear processes for feeding in comments and challenging assumptions; publication of those comments; obligations to pay account to and provide feedback on them.

The second safeguard, transparency, is important in promoting both legitimacy and accountability, and supports inclusion and participation in decision-making. Law should support the widest possible transparency when regulated parties are involved in their own regulation, including on the contents of drafts, and on choices of methodology and uncertainties, in such a way as to provide transparency to those outside (as well as inside) the process. It is also important to know which interests are participating in decision-making, and in this respect, the tensions involved in institutional approaches to protecting personal data are particularly striking. Who actually participates in decision-making needs to be both transparent and contestable (politically if not legally). The justification offered by Sharpston $A G$ for the release of information on who contributes to decisions is compelling: 'the context (an official meeting involving representatives of an industrial group acting as spokesmen for 
their employers, and thus purely in a professional capacity) taken together with the principle of transparency, provided ample justification' for the release of information on participation. ${ }^{163}$ It seems reasonable for those participating in EU governance processes, other than in particular and unusual circumstances, ${ }^{164}$ to accept that the fact of their enrolment will be publicly available. Some might go so far as to urge openness as to precise contributions to discussions; ${ }^{165}$ a difficult balance has to be drawn with effective deliberation, input and output legitimacy. Simply raising that question reminds us that a call for transparency is not simple, and its meaning is not self-evident. ${ }^{166}$

Law potentially has a clear role in bolstering the capacity of the first two safeguards, namely inclusion and transparency. We suggested above that the central role of economic actors in environmental governance raises concerns around the core public law values of legitimacy and accountability; it is unsurprising then that we might turn to some (deceptively) simple public law mechanisms to reinforce these values. The economic and informational advantages of economic actors are pervasive, but those with alternative interests can be at least to some extent empowered through legal rights.

As we discuss in the previous section, public oversight and responsibility can be crucial in promoting a decision-making process that is both legitimate and accountable. Of course, the IED and REACH illustrate as well as any other case that any line between 'economic actors' and 'regulators' may not be clear, given the integration of economic actors into the regulatory process. ${ }^{167}$ Nevertheless, there are two dimensions to this safeguard. First, public authorities play an important role in supervising and scrutinizing the contributions of economic actors. Second, the final decision is officially taken by a public authority; in this regard, the Commission plus comitology process is the preferred way in which political administrative decisions are taken in the EU. The role of law in respect of the third safeguard is relatively limited. In particular, an acknowledgement that the legitimacy of comitology is not sufficiently robust to sidestep any concerns about the preceding process, simply points us back to the need to enhance legitimacy and accountability at all stages of decision-making, in the ways discussed generally in this paper. And the resourcing of public environmental regulators is a perennial political difficulty, one of the very factors that encourages reliance on economic actors. But it is important to guard against the long term concern raised by Grabosky that

\footnotetext{
163 Above n 131.

${ }^{164} \mathrm{Eg}$ whistleblowers, or those participating on potentially personally risky issues such as security; the possibility for 'ordinary' (for want of a better word) non-professional respondents to consultations to remain anonymous may also be necessary to encourage wide participation.

165 As in ClientEarth, above n 133133.

166 See, for example, Fisher, above $n 115$.

167 Freeman, above n 46.
} 
state (or EU) regulatory institutions 'may atrophy, or fail to develop at all'. ${ }^{168}$ It is possible to envisage legal arrangements that would enhance independent, expert regulatory scrutiny of economic actors' contributions to regulation, by paying particular and explicit attention to the need for the exercise of that expertise at crucial moments in the setting up of regulatory institutions: for example, Member State representatives in TWGs could be explicitly directed to exercise independent scrutiny from a public interest regulatory perspective.

Our suggestions build on criteria already implicit in the IED and REACH, and are also consistent with developments elsewhere. It may be worth noting the ways in which periodic amendments to the Environmental Impact Assessment Directive, since its inception in 1985, have incrementally strengthened the processes applied in environmental assessment. ${ }^{169}$ Changes have arguably improved both inclusion and transparency through adding hard detail to the demands made on Member States (for example, requiring information to be made available electronically in the latest iteration). ${ }^{170}$ Information provided by developers, especially their 'environmental statement', is central to the process of environmental assessment that precedes the grant of development consent. Serious doubts have been raised about the quality of this information, and the European Commission has concluded that 'It seems obvious that some kind of quality control is needed in order to provide for a consistent and qualitative body of information.' ${ }^{171}$ It may seem equally 'obvious' that we should insist that specialist (public) regulators develop expertise and expectations by consistently evaluating the quality of the information provided in environmental assessment, a possibility that has however been resisted. ${ }^{172}$ The new Article 5(3) of the Directive, as well as requiring the developer to 'ensure that the environmental impact assessment report is prepared by competent experts', requires the competent authority to 'ensure that it has, or has access as necessary to, sufficient expertise to examine the environmental impact assessment report.' This is relatively bland, and of course may be satisfied by access to private expertise. Nevertheless, this change does indicate that the need for scrutiny is recognised, and that it is feasible for efforts to be made to respond.

\footnotetext{
168 Above n 12, 115.

169 The latest changes in Directive 2014/52/EU amending Directive 2011/92/EU on the assessment of the effects of certain public and private projects on the environment [2014] OJ L124/1. See J. Scott and J. Holder, 'Law and New Environmental Governance in the European Union' in J. Scott and G. de Búrca (eds), Law and New Governance in the EU and US (Oxford: Hart Publishing, 2006)

170 See Arts 5 and 6.

171 European Commission, Study concerning the report on the application and effectiveness of the EIA Directive (final report) (2009) at p16.

172 See eg, The Government's Response to the Royal Commission's Twenty-third Report on Environmental Planning (2003) Cm 5887, at 12.
} 
Simply put, the three safeguards identified in the previous section need to be implemented with more care, and with greater sensitivity to their limitations. In particular, the fragility, in their different ways, of both environmental interest groups and comitology, indicate that there are no complete solutions to balance, or sidestep, the role of economic actors. This leads us to advocate smaller steps. There is always a danger that imposing what are essentially public law values in a de-centred decision-making context will frustrate the important benefits that economic actors bring to regulation. Perhaps trade-offs are necessary: accountability and legitimacy to broader publics for expertise, efficiency and acceptability to regulated parties. The role of law is potentially crucial, and it is the responsibility of both legislatures and the courts ${ }^{173}$ to support the fullest possible participation and transparency. Recognition of the limited legitimacy of the Commission plus comitology option further emphasises the need to pay more attention to the nature and processes of all steps of decision-making.

\section{Conclusions}

As Schepel puts it, the 'legal imperative' is 'to promote the procedural integrity' of our process, 'to diversify its membership, to enhance its knowledge base, and to broaden its ethos'. ${ }^{174}$ We have identified three significant overlapping and non-exhaustive mechanisms by which efforts are made in EU environmental law to enhance the legitimacy and accountability of economic actor enrolment in decision-making. The first two, inclusion and transparency, are commonly urged in respect of complex forms of governance. Law can play a crucial role in ensuring greater inclusion and transparency, and importantly, must not be used to block those values. In part, the third safeguard, public oversight and responsibility, feeds into the first two: the inclusion of and scrutiny by public regarding institutions contributes important resources of legitimacy and accountability to these processes. In part it also attempts to do something else, through an effort to reassert a theoretical model of delegation and agency that is difficult to maintain in the context of high levels of technical complexity and expertise. But equally, this is an insistence that political decisions should be taken by politically legitimate bodies; and that is a value worth striving for, albeit one that simply takes us back to the need to ensure inclusion and transparency at every stage of the process.

Drawing conclusions is obviously difficult, when we have observed both the necessity for economic actor enrolment, and its inevitable challenges. Condemning economic actor involvement is obviously not an option. Instead, we must endeavour to render these sites of

\footnotetext{
173 Scott and Sturm, above n 157.

174 Schepel, above $\mathrm{n} 11$ at 413.
} 
private governance as legitimate and as accountable as possible. Grainne de Búrca's discussion of 'democratic striving' is set in the global context, where the challenges and context are different; certainly, there is no indication that scholars share a desire to 'avoid or bracket' the 'democracy problem' in the EU. ${ }^{175}$ Nevertheless, we see some parallels between the apparent unanswerability of the challenges posed by enrolment of economic actors, and those of democratising the 'significant public-oriented policies ... being established through complex transnational governance processes'. ${ }^{176}$ 'Striving' to enhance the 'building blocks' of legitimacy and accountability that are easily avoided in this context is equally important.

EU law recognises the challenges posed by economic actor enrolment, and has provided some sensible responses. The three safeguards identified here do however need to be addressed with much more rigour and consistency: broad transparency and inclusion should be considered absolutely core safeguards when economic actors are involved in governing. Inclusion and transparency are not unintrusive or straightforward values, but equally, reliance on economic actors is far from a small matter. Further, and learning some of the lessons of the financial crisis, it is important that the enrolment of economic actors is not perceived to be a cheap or easy option for public regulators; the continued demand for resources of expertise and time in the public sector is significant. ${ }^{177}$ Similarly, we should note that public-led command and control initiatives are still core to the regulatory landscape. ${ }^{178}$ The two cases discussed here indeed indicate that command and control and the enrolment of economic actors are by no means incompatible; command and control relies in part on the resources of economic actors. The challenges of legitimacy and accountability, and their reflection in law, are not easily avoided.

\footnotetext{
175 De Búrca, above $\mathrm{n} 4$, at 226.

176 De Búrca, above $\mathrm{n} 4$, at 224.

177 See for example Ford, above n 134 and Black, above n 52.

178 C. Scott, 'Governing without Law or Governing without Government? New-ish Governance and the Legitimacy of the EU' (2009) European Law Journal 160.
} 